\title{
Rapsynoid/Partner of Inscuteable Controls Asymmetric Division of Larval Neuroblasts in Drosophila
}

\author{
Marie-Laure Parmentier, ${ }^{1}$ Daniel Woods, ${ }^{2}$ Steve Greig,, ${ }^{1}$ Phu G. Phan, ${ }^{1}$ Anna Radovic,, ${ }^{2}$ Peter Bryant, ${ }^{2}$ and \\ Cahir J. O'Kane ${ }^{1}$ \\ ${ }^{1}$ Department of Genetics, University of Cambridge, Cambridge CB2 3EH, United Kingdom, and 2Developmental Biology \\ Center, University of California, Irvine, California 92697
}

\begin{abstract}
Asymmetric cell division generates daughter cells with different developmental fates. In Drosophila neuroblasts, asymmetric divisions are characterized by (1) a difference in size between the two daughter cells and (2) an asymmetric distribution of cell fate determinants, including Prospero and Numb, between the two daughter cells. In embryonic neuroblasts, the asymmetric localization of cell fate determinants is under the control of the protein Inscuteable (Insc), which is itself localized asymmetrically as an apical crescent. Here, we describe a new Drosophila protein, Rapsynoid (Raps), which interacts in a two-hybrid assay with the signal transduction protein $\mathrm{G} \alpha \mathrm{i}$. We show that Raps is localized asymmetrically in dividing larval neuroblasts
\end{abstract}

Neuroblasts are the stem cells responsible for the formation of the larval and adult nervous systems in Drosophila. Embryonic neuroblasts give rise to the neurons of the larval nervous system, whereas larval neuroblasts produce new neurons of the adult nervous system. They undergo repeated divisions to bud off some ganglion mother cells (GMCs), each of which divides once more to generate two neurons (Goodman and Doe, 1993; Truman et al., 1993). The neuroblast divisions are asymmetric because (1) the GMC is smaller than the neuroblast, and (2) some molecular components are asymmetrically localized in the neuroblast and are consequently differentially distributed in the neuroblast and the newly formed GMC. This is the case for the proteins Prospero and Numb in embryonic neuroblasts (Hirata et al., 1995; Knoblich et al., 1995; Spana and Doe, 1995). Indeed, embryonic neuroblasts divide along their apical-basal axis after their delamination from the neuroectodermal epithelium and bud off GMCs on their basal face. One of the molecules concentrated on the basal face of neuroblasts during division is Prospero (Pros), which is a homeodomain-containing transcription factor (Hirata et al., 1995; Knoblich et al., 1995; Spana and Doe, 1995). After cytokinesis, Pros is rapidly translocated into the nucleus of the

\footnotetext{
Received Feb. 16, 2000; revised April 13, 2000; accepted April 24, 2000.

This work was supported by Wellcome Trust Traveling Fellowship 05133 to M.-L.P., by UK Biotechnology and Biological Sciences Research Council Grant ICS00761 to C.J.O., and by Grant CA66 263 to P.B. We thank W. Chia, C. Klämbt, and C. Doe for providing antibodies and F. Van Eeden for providing stocks and genomic DNA. We thank J. Knöblich and W. Chia for useful discussions before publication, and we thank A. Ramaekers, J.-P. Pin, and J. Bockaert for critical reading of this manuscript.

Correspondence should be addressed to Marie-Laure Parmentier, Centre National de la Recherche Scientifique-Institut National de la Santé et de la Recherche Médicale de Pharmacologie et Endocrinologie, 141 rue de la Cardonille 34094 Montpellier Cedex 05 France. E-mail: parment@ccipe.montp.inserm.fr, or to Cahir O'Kane, Department of Genetics, University of Cambridge, CB23EH Cambridge, UK.

Dr. Woods's present address: Inscent Inc., Suite 317, 4251 Campus Drive, Irvine, CA 92612.

Dr. Greig's present address: School of Biological Sciences, University of Sussex, Falmer, Brighton BN1 9QG, UK.

Copyright (C) 2000 Society for Neuroscience $\quad 0270-6474 / 00 / 200001-05 \$ 15.00 / 0$
}

and colocalizes with Insc. Moreover, in raps mutants, the asymmetric divisions of neuroblasts are altered: (1) Insc is no longer asymmetrically localized in the dividing neuroblast; and (2) the neuroblast division produces two daughter cells of similar sizes. However, the morphologically symmetrical divisions of raps neuroblasts still lead to daughter cells with different fates, as shown by differences in gene expression. Our data show that Raps is a novel protein involved in the control of asymmetric divisions of neuroblasts.

Key words: neuroblast; asymmetric division; development; G-protein; tetratricopeptide repeat; GoLoco motif
GMC and is responsible for GMC fate (Doe et al., 1991; Vaessin et al., 1991; Matsuzaki et al., 1992). On the other hand, there are some molecules that are concentrated as crescents on the apical side of neuroblasts, including Inscuteable (Kraut et al., 1996) and Bazooka (Kuchinke et al., 1998; Schober et al., 1999; Wodarz et al., 1999). Bazooka is necessary to set up the apical-basal polarity of the neuroblasts when they delaminate from the neuroectodermic epithelium and is required for asymmetric localization of Inscuteable (Kuchinke et al., 1998; Schober et al., 1999; Wodarz et al., 1999). Inscuteable (Insc) is necessary for several aspects of neuroblast asymmetric division, including (1) the orientation of the mitotic spindle in the apical-basal direction and (2) the asymmetric distribution of Prospero, Numb, and Miranda (Kraut et al., 1996; Shen et al., 1998; Tio et al., 1999). However, the cell size asymmetry of neuroblast divisions is not affected in insc embryos (Buescher et al., 1998).

Here, we describe a new Drosophila protein, Rapsynoid (Raps), which interacts in a two-hybrid assay with the signal transduction protein G $\alpha$ i. An important role of Raps in controlling asymmetric neuroblast division is shown by the findings that (1) it is asymmetrically localized, like Insc, in neuroblasts; (2) it is required for Insc asymmetric localization; and (3) it is required for the difference of size between the neuroblast and the GMC during division.

This article is published in The Journal of Neuroscience, Rapid Communications Section, which publishes brief, peer-reviewed papers online, not in print. Rapid Communications are posted online approximately one month earlier than they would appear if printed. They are listed in the Table of Contents of the next open issue of JNeurosci. Cite this article as: JNeurosci, 2000, 20:RC84 (1-5). The publication date is the date of posting online at www.jneurosci.org.

http://www.jneurosci.org/cgi/content/full/4321 


\section{MATERIALS AND METHODS}

Yeast two-hybrid screen. A construct encoding the complete sequence of Drosophila G $\alpha$ i was used as a bait to screen a Drosophila embryonic cDNA library (Granderath et al., 1999).

Fusion protein and generation of anti-Raps antibody. A fusion protein containing amino acid residues $238-655$ of the Raps coding region was expressed as a His-tagged protein and purified using nickel-coupled Sepharose. Rats were immunized and boosted using standard methods. The serum giving the best immunostaining was selected, and the IgG fraction was purified. Specificity of this antibody was confirmed by Western blots of larval extracts and by the lack of staining in the brain of mutant larvae.

Immunocytochemistry and confocal microscopy. The larval brains were dissected rapidly in PBS and fixed in $4 \%$ paraformaldehyde for $30 \mathrm{~min}$. The following primary antibodies were used: guinea pig polyclonal anti-Dlg (1:1000), rat polyclonal anti-Raps (1:250; this work), rabbit polyclonal anti-Insc (1:1000; W. Chia, Institute of Molecular and Cell Biology, Singapore), mouse monoclonal anti- $\beta$-tubulin E7 (M. Klymkowsky, obtained from the Developmental Studies Hybridoma Bank, maintained by The University of Iowa, Department of Biological Sciences, Iowa City, IA), and mouse monoclonal anti-Prospero (1:5, C. Klämbt, Institut fur Neurobiologie, Muenster, Germany). Fluorescent secondary antibodies were from Jackson ImmunoResearch (West Grove, PA). Images were obtained using a Leica confocal microscope (MultiImaging Center, University of Cambridge) and a Bio-Rad MRC 1024 laser scanning confocal microscope (Centre Regional d'Imagerie Cellulaire, Montpellier, France) and processed using Adobe Photoshop (Adobe Systems, Mountain View, CA).

P-element mobilization. We used the line 1(3)S031807 that carries a P-element derivative (Deak et al., 1997) inserted $\sim 2.5 \mathrm{~kb}$ upstream of the raps transcription unit at cytological location 98A-B. This insertion is homozygous viable. The P-element, carrying the white ${ }^{+}$gene, was mobilized using $\mathrm{P}[r y+, \Delta 2-3](99 \mathrm{~B})$ as a transposase source. Approximately 300 independent white revertant lines were analyzed by PCR and, in some cases, by Southern blot. Several deletion events affecting the raps coding region were recovered.

Germ line transformation using a raps transgene. To produce a fulllength raps cDNA under the control of the hsp70 promoter, a NotI-KpnI cDNA fragment [expressed sequence tag (EST) GM02189] was cloned into pUAST cut with the same enzymes. The cDNA fragment was then subcloned in pCaspeR-hs in the $X b a I$ site of the polylinker. The standard procedures (Spradling, 1986) were used to obtain germ line transformants. Rescue experiments were performed at $25^{\circ} \mathrm{C}$, using lines carrying the transgene on the second chromosome.

\section{RESULTS}

\section{Raps is a Drosophila homolog of the human LGN protein}

To identify proteins that interact with Drosophila Gai, we performed a yeast two-hybrid interaction screen using this protein as a bait (Granderath et al., 1999). The interacting clones that were identified included eight overlapping clones that encoded a new Drosophila protein called Raps. We obtained a cDNA (GM02189) containing the complete coding sequence from the Berkeley Drosophila Genome Project EST collection. As shown in Figure 1, $A$ and $B$, rapsynoid cDNA encodes a 659 -amino acid protein that contains seven tetratricopeptide repeats (TPRs), which serve as protein interaction motifs and regulatory domains in various proteins (Blatch and Lassle, 1999). These repeats are similar ( $23 \%$ identity and $43 \%$ similarity) to those existing in rapsyn, a mouse protein, hence the name rapsynoid. However, Raps is not a Drosophila homolog of rapsyn. It is more similar to the human protein LGN (48\% identity) and the rat protein activator of G-protein signaling 3 (AGS3) (45\% identity) and lacks homology with the C-terminal region of rapsyn. As with Raps, LGN was identified because of its ability to interact with ${\mathrm{G} \alpha \mathrm{i}_{2}}_{2}$ in a twohybrid assay (Mochizuki et al., 1996). AGS3 has been shown to activate $\mathrm{G} \alpha \mathrm{i}$ proteins independently of G-protein-coupled receptors (Takesono et al., 1999). LGN and AGS3 possess, at their C terminus, four motifs, called GoLoco sequences (Siderovski et al., 1999) found in numerous proteins that interact with Goi/o. Raps contains three such GoLoco consensus sequences near its $\mathrm{C}$ terminus (Fig. 1 $A, C$ ). The smallest Raps sequence that is able to interact with $\mathrm{G} \alpha \mathrm{i}$ (from aa 560 to 659 ) in a two-hybrid assay contains only the most C-terminal complete GoLoco motif, sug-
$\mathbf{A}$

MSSLSASAENVSSLGLGSGGGGTNSHDGNSQQGSGSDGGSSMCLELALEG 50 ERLCKAGDCRAGVAFFQAAIQAGTEDLRTLSAIYSQLGNAYFYLGDYNKA 100 MOYHKHDLTIAAKSMNDRLGEAKS SNLGNTI.KVMGRPDEAAICCERHLTL 150 AROLGDRLSEGRALYNLGNVYHAKGKHLGORNPGKFGDDVKEALTRAVEF 200 YQBNLKLMRDLGDRGAQGRACGNLGNTYYLLGDFOAAIBHHOERLRIARE 250 $\begin{array}{ll}\text { YQBNLKLMRDLGDRGAQGRACGNLGNTYYLLGDFQAAIBHHQERLRIARE } & 250 \\ \text { FGDRAAERRANSNLGNSHIFLGQFEDAAEHYKRTLALAVBLGEREVEAQS } & 300\end{array}$ CYSLGNTYTLLHEFNTAIBYHNRHLAIAOELGDRIGEARACWSLGNAHSA 350 IGGHERALKYAEOHLQLAKELHDPVGESTARVNISDLRKLLGMPDSEPSP 400 TEEEARSTASDHSASGNOSDGSGNSOGRMVRVRROSMEOLDLIKITPDGK 450 RMOERKI RAOATRKAKDDDPEEMI SRSOSKRMDDORCSIKVNPSGAPAVA 500 TMEA TGATR DDDFLDMLMRCQGSRLEEQRSELPRPNVTMDAEARAPPRSVPEAAVPGAP 600 RGQTGRGATVPDEDFFSLIMKVQSGRMEDQRASIPFRNANNNNNSRSNNN 650 GSAGGAGK

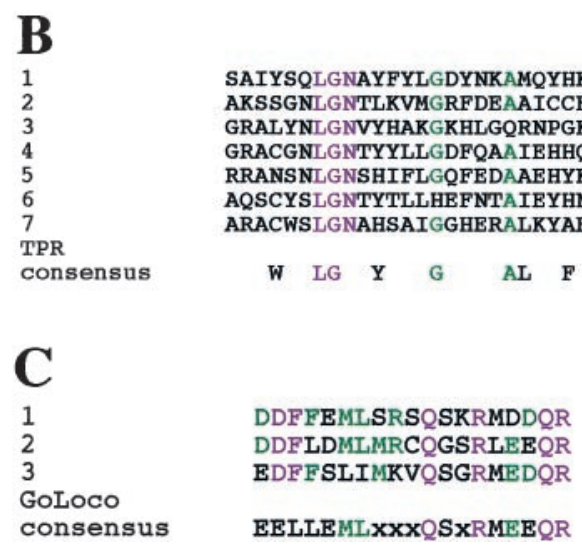

Figure 1. A, Sequence of Raps protein (accession number AJ272067). Tetratricopeptide repeats (34-amino acid repeats) are highlighted in blue. The GoLoco consensus sequences are highlighted in pink. $B$, Alignment of the seven Raps TPR sequences (1-7). Amino acids conserved in the seven repeats are highlighted in purple, and the residues conserved in six of the seven sequences are shown in green. The general TPR consensus sequence, derived from a collection of 250 TPR motifs (spanning all major taxons) and described by Kyrpides and Woese (1998) is shown at the bottom. $C$, Alignment of the three Raps GoLoco motifs. Amino acids conserved in the three repeats are highlighted in purple, and the residues conserved in two of the three sequences are shown in green. The general GoLoco consensus sequence described by Siderovski et al. (1999) is shown at the bottom.

gesting that this copy of the motif is sufficient to allow interaction with G $\alpha$ i.

\section{Raps colocalizes with Insc in the larval CNS}

To study the localization of Raps, we raised an antibody against a fusion protein containing Raps without the four first TPR repeats. We focused on the expression of Raps during larval stages because some of the rapsynoid mutants are lethal at this stage. In the larval CNS, the neuroblasts are derived from quiescent embryonic neuroblasts (Truman and Bate, 1988; Prokop and Technau, 1991). They are also polarized and produce small GMCs constantly at the same pole (Fig. 2A; Ito and Hotta, 1992). However, there is no clear apical-basal orientation perpendicular to the surface of the brain, and different neuroblasts are polarized in different orientations (data not shown). As in embryonic neuroblasts, Insc is asymmetrically localized and forms a crescent at the face opposite to the future GMC during metaphase (Fig. $2 A$ ). Such a crescent is not visible during interphase (data not shown), although this is reported in embryonic neuroblasts (Kraut et al., 1996).

Raps is expressed in the neuroblasts in interphase (Fig. 2B). It is localized mainly cortically (see the expression of the septate junction protein Discs-Large), and the staining is punctate, as opposed to the Discs-Large staining that is homogenously present all along the plasma membrane (Woods et al., 1997). Raps localization is different in dividing neuroblasts. There is a clear 

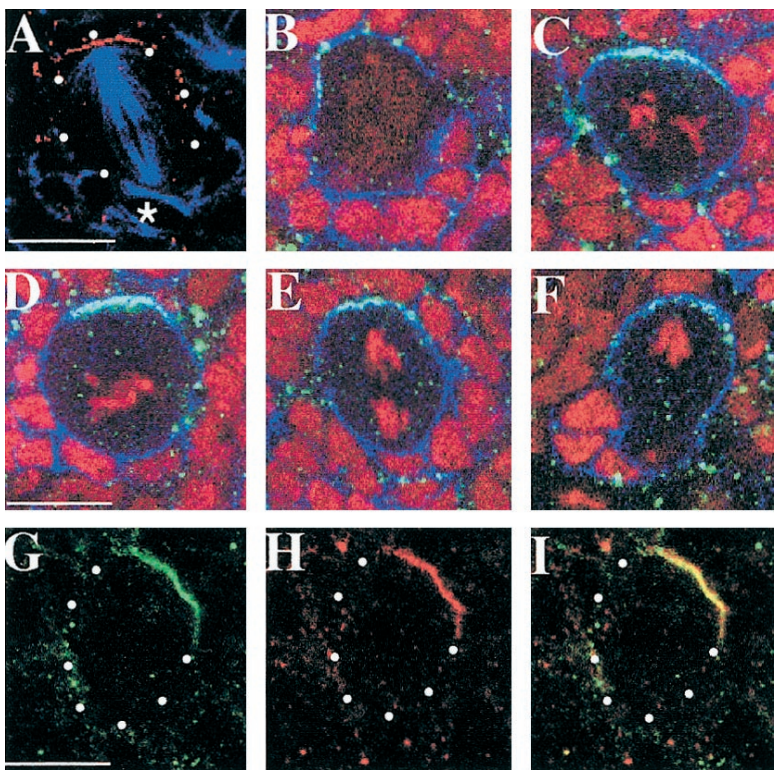

Figure 2. $A$, Immunostaining against $\beta$-tubulin (blue) and Insc (red) in a metaphase neuroblast. The large cell with a metaphase spindle is the neuroblast (outlined by white dots). The $\beta$-tubulin staining labels the cortex of the adjacent GMCs, which are localized on one side of the neuroblast. The youngest GMC (in the axis of the neuroblast spindle) is shown by a star. We observe an Insc crescent, which is located on the side opposite to the one where the GMCs bud off. $B-F$, Immunostaining against Discs-Large (blue) and Raps (green) with the DNA stain propidium iodide $(r e d)$ in interphase $(B)$, prophase $(C)$, metaphase $(D)$, anaphase $(E)$, and telophase $(F)$ neuroblasts. Discs-Large is localized cortically in cells (neuroblast and GMCs). Raps staining is punctate during interphase, whereas it forms a crescent during division. $G-I$, Immunostaining against Raps $(G)$ and Insc $(H)$ in a dividing neuroblast (outlined by white dots) shows a crescent of these two proteins. The costaining $(I)$ shows colocalization of Raps and Insc. Scale bar, $10 \mu \mathrm{m}$.

crescent of Raps protein during prophase, metaphase, and anaphase, which disappears during telophase (Fig. $2 C-F$ ). Double staining for Raps and Insc (Fig. $2 G-I$ ) showed colocalization of the Raps and Insc crescents in all dividing neuroblasts observed $(n=26)$.

Because Insc is involved in the control of asymmetric division of neuroblasts, the colocalization of Raps with Insc suggested a possible role of Raps in the same process.

\section{In raps mutant, Insc asymmetrical localization in neuroblasts is altered}

To analyze Raps function in neuroblasts, we obtained flies mutant for rapsynoid by imprecise excision of a P-element, 1(3)S031807 (Deak et al., 1997), adjacent to the rapsynoid gene. The P-element is situated in an intron of another gene proximal to rapsynoid, orientated in the opposite direction, and represented by EST LD02456 (Fig. 3A). We obtained one deletion affecting the first exon of the left gene. This deletion ( $\operatorname{raps}^{86}$ ) is homozygous viable and does not show any detectable mutant phenotype in any of the experiments described below. We obtained additional deletions affecting the left gene and rapsynoid $\left(\operatorname{raps}^{83}\right.$, raps ${ }^{179}$, and raps ${ }^{193}$; Fig. $3 A$ ). Flies homozygous for any of these deletions die as young pupae and, based on their phenotype over Df(3R)IR16 that deletes the whole raps gene, behave genetically as strong hypomorphs for the phenotypes studied.

Because we observed colocalization of Raps with Insc in wild type, we looked for any disruption of Insc localization in raps mutants. The Insc crescent fails to form in the mutant metaphase neuroblasts, and only a punctate staining similar to that seen in interphase is visible (Fig. $3 B-D$ ). This phenotype is rescued in all raps mutants when we add a rapsynoid transgene under the
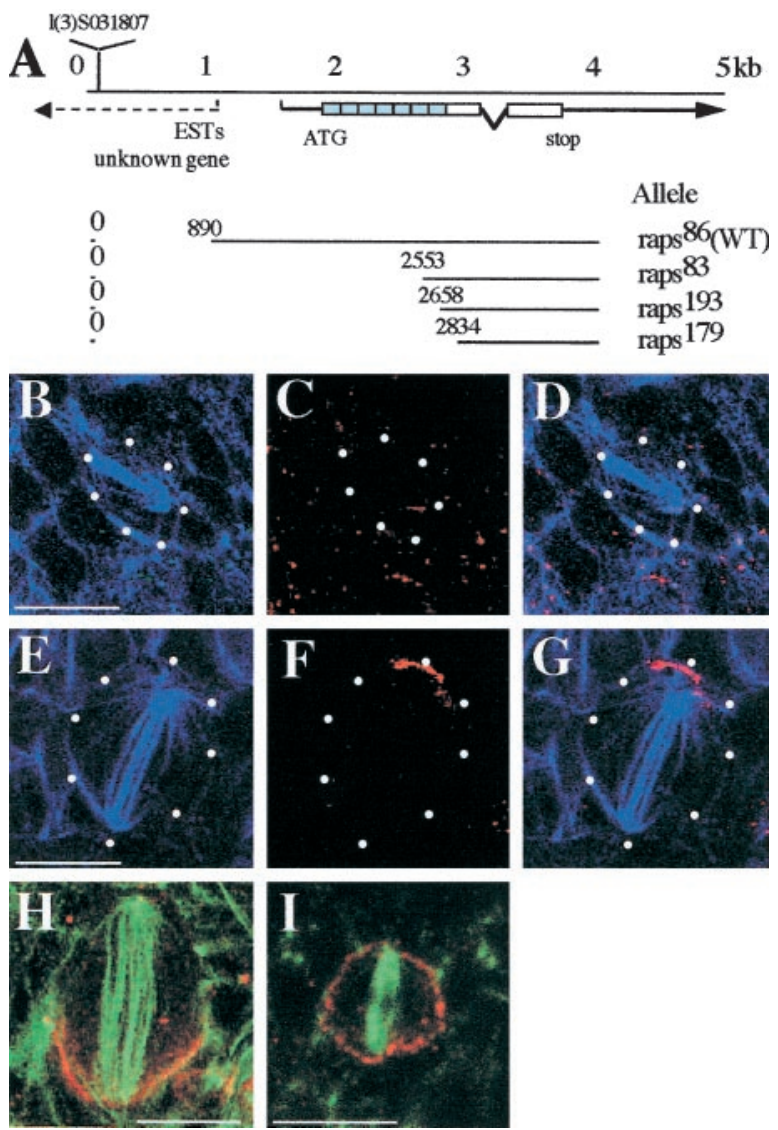

Figure 3. A, Genomic region of the raps gene. Position 0 corresponds to the rightmost nucleotide of the $\mathrm{P}$ element insertion in 1(3)S031807. Comparison of cDNA and genomic sequences shows only one intron in the raps gene. The first exon contains all the TPR domains (blue boxes). The deletions obtained by excision of the P element in 1(3)S031807 are symbolized by gaps, and their nucleotide coordinates are shown. $B-D$, Immunostaining against $\beta$-tubulin $(B)$ and Insc $(C)$ in a raps ${ }^{193}$ mutant. The costaining is shown in $D$. There is no Insc crescent in the dividing neuroblast [outlined by white dots, outline visualized with $\beta$-tubulin staining $(B)$ and Discs-Large staining (data not shown)]. Note that the neuroblast is smaller than in the wild-type situation. Scale bar, $10 \mu \mathrm{m}$. $E-G$, Immunostaining against $\beta$-tubulin $(E)$ and Insc $(F)$ in a $h s$-raps/hs-raps; raps $^{193} /$ raps $^{193}$ larva. The costaining is shown in $G$. There is a recovery of the asymmetrical localization of Insc, which is similar to the wild-type situation (compare with Fig. $2 A-C$ ). Scale bar, is $10 \mu \mathrm{m}$. $H$, I, Immunostaining against Miranda (red) and $\beta$-tubulin (green) in a wild-type and raps $^{193}$ mutant. Scale bar, $10 \mu \mathrm{m}$.

control of the hsp70 promoter. The basal expression, at $25^{\circ} \mathrm{C}$, of two copies of the transgene is sufficient for a complete rescue of Insc asymmetrical localization (Fig. $3 E-G$ ). We thus conclude that Raps is necessary for the asymmetrical localization of Insc in neuroblasts.

We also studied the effect of a raps mutation on the localization of Miranda, whose localization on the GMC side of the neuroblast during division is dependent on Insc function (Shen et al., 1998). As expected, Miranda is asymmetrically localized in wildtype mitotic neuroblasts, but is no longer asymmetrically localized in raps mutant neuroblasts (Fig. $3 H, I$ ).

\section{In raps mutant, there is an increase in symmetrical neuroblast division}

An important aspect of neuroblast asymmetric divisions is their morphology. In wild-type third-instar larvae, at day 5 after egg laying, all neuroblast divisions are morphologically asymmetric, producing a GMC that is one-eighth the size of the neuroblast (Figs. 2, 4D). This is not the case in raps mutants, where $28 \%$ of 

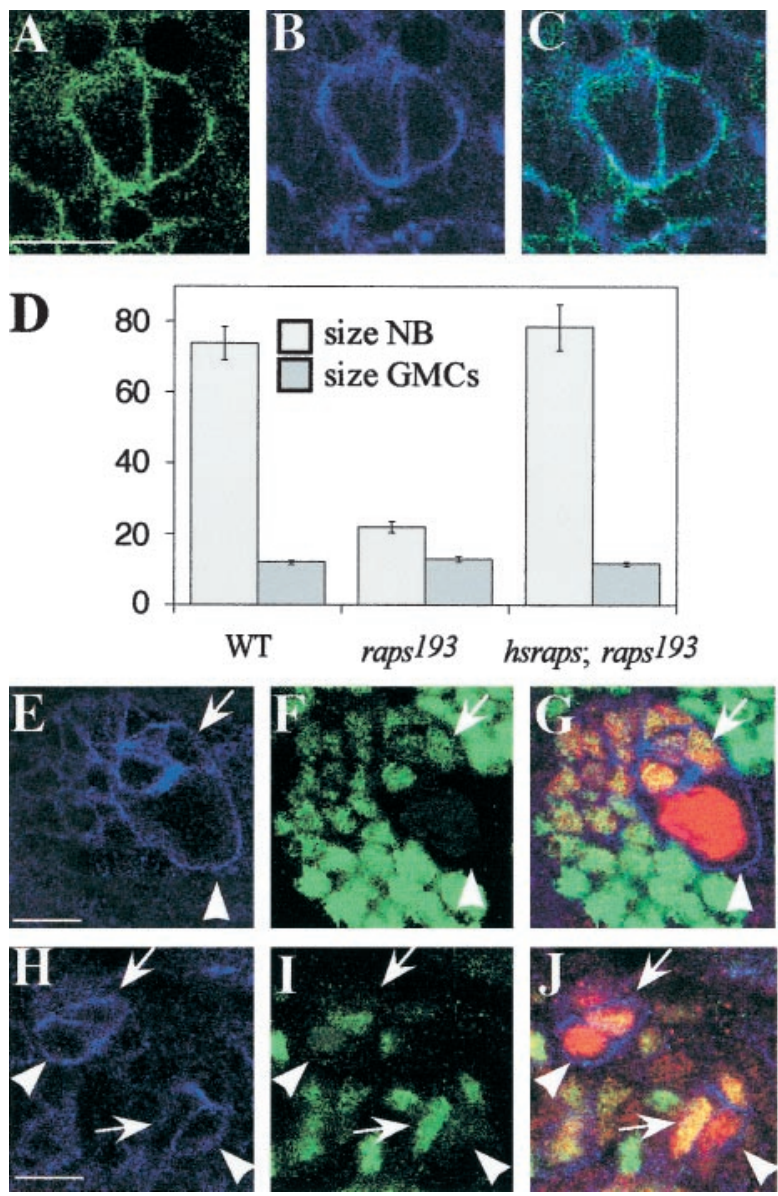

Figure 4. $A-C$, Immunostaining against Discs-Large $(A)$ and $\beta$-tubulin $(B)$ in a raps ${ }^{193}$ mutant. The costaining is shown in $C$. We can see two adjacent cells, coming from a symetrical division of a neuroblast. Scale bar, $10 \mu \mathrm{m}$. D, Quantification of neuroblast and GMC sizes in 108-hr-old wild-type raps ${ }^{193}$ mutants and rescued hs-raps/hs-raps; raps ${ }^{193} /$ raps $^{193}$ larvae. The size of cells was estimated in square micrometers by measuring the area of the largest section of each cell from a $z$-series of confocal sections. $E-J$, Immunostaining against Discs-Large $(E, H$, blue), Prospero $(F, I$, green $)$, and the deadpan-driven $\beta$-galactosidase $(D, J$, red $)$. The triple staining is shown in $G$ and $J$. In the wild-type situation $(E-G)$, the neuroblast (white arrowhead) is much larger than the GMCs (white arrow) and does not express nuclear Prospero. In raps ${ }^{193}$ mutants $(H-J)$, the neuroblasts (white arrowheads) have sizes similar to GMCs (white arrow) but express no Prospero, whereas the GMCs do express deadpan-LacZ and high levels of Prospero.

neuroblasts divisions are morphologically symmetrical (Fig. 4A$C)$. Correlatively, the neuroblasts of third-instar larvae are smaller than in wild type, and their size approaches that of GMCs (Fig. 4D). These phenotypes are rescued in the presence of a rapsynoid transgene (data not shown).

We have used molecular markers to determine whether the loss of morphological asymmetry in dividing raps neuroblasts reflects a defect in cell fate determination during these divisions. We used a neuroblast marker (deadpan-LacZ) that is expressed at a high level in neuroblasts and at a low level in GMCs (Bier et al., 1992) and a GMC marker, Prospero, which is expressed in the nuclei of GMCs but not in the nuclei of neuroblasts (Hirata et al., 1995; Knoblich et al., 1995; Manning and Doe, 1999). In raps mutants, a neuroblast-like cell expresses the neuroblast marker and no Prospero (or expresses Prospero very weakly), whereas the other daughter cell expresses Prospero strongly (Fig. 4E-J). The results we obtain show that although the division is morphologically symmetrical, and although Insc is not apically localized, there is still some asymmetry in the division to lead to the differenciation of two dissimilar daughter cells.

\section{DISCUSSION}

Our results show that Rapsynoid is a multidomain protein, containing seven TPR motifs at its $\mathrm{N}$ terminus and three GoLoco consensus sequences at its $\mathrm{C}$ terminus. Our two-hybrid data show that the part of the protein containing the GoLoco sequences is involved in the interaction of Raps with G $\alpha$ i. However, the function of the TPR domains is unknown. After LGN and AGS3, the TPR domains of Raps are most similar to those of rapsyn. Rapsyn is involved in the clustering of nicotinic acetylcholine receptors at the mammalian neuromuscular junction (Gautam et al., 1995) and its TPR domains are required for the ability to form clusters (Ramarao and Cohen, 1998). These domains could have a similar function in Rapsynoid, because we always observe a punctate Raps staining, which could correspond to some local clusters of the protein.

Our data show that Rapsynoid is asymmetrically localized in dividing larval neuroblasts and colocalizes with Insc. Morover, Insc localization is affected in raps mutants, showing that Raps is required for the asymmetrical Insc localization. This could be attributable to either (1) a direct interaction of Raps and Insc at the pole of the neuroblasts or (2) an indirect interaction. More biochemical experiments will be needed to understand the interaction between Raps and Insc.

We show that Rapsynoid interacts with G $\alpha$ i in a two-hybrid assay. Moreover, AGS3, a rat homolog of Raps, is able to activate $\mathrm{G}_{\alpha \mathrm{i}_{2}}$ in yeast, which confirms the interaction seen in the yeast two-hybrid experiment. It is thus possible that some Gi/o heterotrimeric proteins are involved in the control of asymmetric divisions of neuroblasts. We have not yet been able to test for asymmetrical concentration of $\mathrm{G} \alpha \mathrm{i}$ or $\mathrm{G} \alpha \mathrm{o}$ with Raps because of the lack of antibodies directed against the Drosophila proteins. However, a role of heterotrimeric G-proteins has been shown in the orientation of divisions in the early embryo of Caenorhabditis elegans (Zwaal et al., 1996). The orientation of the mitotic spindle is controlled by the same molecular system that controls asymmetric division, as shown, for example, by altered spindle orientation in bazook $a$ and insc mutants. Together with the C. elegans results, our results suggest that a heterotrimeric protein might be involved in the asymmetric divisions of neuroblasts.

In addition to a defect in Insc and Miranda asymmetrical localization, the frequency of morphologically symmetrical divisions is increased in raps mutants. This shows that the raps mutation affects not only the asymmetric distribution of intracellular components but also a mechanism responsible for the asymmetry of cell size (Kaltschmidt et al., 2000). It is already known that the mechanisms controlling the asymmetry of cell size and the asymmetric distribution of components are distinct from one another. Indeed, some cells (sensory organ precursors and GMCs) divide into two cells of similar size but with different intracellular compositions (Kraut et al., 1996; Buescher et al., 1998; Manning and Doe, 1999). However, raps is the first reported mutation that affects both aspects of asymmetric neuroblast division. In contrast, in insc and bazooka mutants, although the molecular aspects of asymmetry are clearly affected, the divisions still give rise to a GMC much smaller than the neuroblast (Buescher et al., 1998; Schober et al., 1999; Wodarz et al., 1999). One hypothesis to explain this situation could be that Raps is a component acting upstream of Insc in the neuroblasts, so that the effects of the raps mutation are broader than the effects of the insc mutation and comprise the control of the difference of size of the daughter cells.

A phenotype in neuroblast asymmetric division attributable to mutations in the same gene has also been reported in two recent papers (Schaefer et al., 2000; Yu et al., 2000). 


\section{REFERENCES}

Bier E, Vaessin H, Younger-Shepherd S, Jan LY, Jan YN (1992) deadpan, an essential pan-neural gene in Drosophila, encodes a helix-loophelix protein similar to the hairy gene product. Genes Dev 6:2137-2151.

Blatch GL, Lassle M (1999) The tetratricopeptide repeat: a structural motif mediating protein-protein interactions. Bioessays 21:932-939.

Buescher M, Yeo SL, Udolph G, Zavortink M, Yang X, Tear G, Chia W (1998) Binary sibling neuronal cell fate decisions in the Drosophila embryonic central nervous system are nonstochastic and require inscuteable-mediated asymmetry of ganglion mother cells. Genes Dev 12:1858-1870.

Deak P, Omar MM, Saunders RD, Pal M, Komonyi O, Szidonya J, Maroy P, Zhang Y, Ashburner M, Benos P, Savakis C, Siden-Kiamos I, Louis C, Bolshakov VN, Kafatos FC, Madueno E, Modolell J, Glover DM (1997) P-element insertion alleles of essential genes on the third chromosome of Drosophila melanogaster: correlation of physical and cytogenetic maps in chromosomal region 86E-87F. Genetics 147:1697-1722.

Doe CQ, Chu-LaGraff Q, Wright DM, Scott MP (1991) The prospero gene specifies cell fates in the Drosophila central nervous system. Cell 65:451-464.

Gautam M, Noakes PG, Mudd J, Nichol M, Chu GC, Sanes JR, Merlie JP (1995) Failure of postsynaptic specialization to develop at neuromuscular junctions of rapsyn-deficient mice (see comments). Nature 377:232-236.

Goodman CS, Doe CQ (1993) Embryonic development of the Drosophila central nervous system. In: The development of Drosophila melanogaster (Bate M, Martinez Arias A, eds), pp 1131-1206. Cold Spring Harbor, NY: Cold Spring Harbor Laboratory.

Granderath S, Stollewerk A, Greig S, Goodman CS, O'Kane CJ, Klambt C (1999) loco encodes an RGS protein required for Drosophila glial differentiation. Development 126:1781-1791.

Hirata J, Nakagoshi H, Nabeshima Y, Matsuzaki F (1995) Asymmetric segregation of the homeodomain protein Prospero during Drosophila development. Nature 377:627-630.

Ito K, Hotta Y (1992) Proliferation pattern of postembryonic neuroblasts in the brain of Drosophila melanogaster. Dev Biol 149:134-148.

Kaltschmidt JA, Davidson CM, Brown NH, Brand AH (2000) Rotation and asymmetry of the mitotic spindle direct asymmetric cell division in the developing central nervous system. Nat Cell Biol 2:7-12.

Knoblich JA, Jan LY, Jan YN (1995) Asymmetric segregation of Numb and Prospero during cell division. Nature 377:624-627.

Kraut R, Chia W, Jan LY, Jan YN, Knoblich JA (1996) Role of inscuteable in orienting asymmetric cell divisions in Drosophila. Nature 383:50-55.

Kuchinke U, Grawe F, Knust E (1998) Control of spindle orientation in Drosophila by the Par-3-related PDZ-domain protein Bazooka. Curr Biol 8:1357-1365.

Kyrpides NC, Woese CR (1998) Tetratrico-peptide-repeat proteins in the archaeon Methanococcus jannaschii. Trends Biochem Sci 23:245-247.

Manning L, Doe CQ (1999) Prospero distinguishes sibling cell fate without asymmetric localization in the Drosophila adult external sense organ lineage. Development 126:2063-2071.

Matsuzaki F, Koizumi K, Hama C, Yoshioka T, Nabeshima Y (1992) Cloning of the Drosophila prospero gene and its expression in ganglion mother cells. Biochem Biophys Res Commun 182:1326-1332.

Mochizuki N, Cho G, Wen B, Insel PA (1996) Identification and cDNA cloning of a novel human mosaic protein, LGN, based on interaction with G alpha i2. Gene 181:39-43.

Prokop A, Technau GM (1991) The origin of postembryonic neuroblasts in the ventral nerve cord of Drosophila melanogaster. Development $111: 79-88$

Ramarao MK, Cohen JB (1998) Mechanism of nicotinic acetylcholine receptor cluster formation by rapsyn. Proc Natl Acad Sci USA 95:4007-4012.

Schaefer M, Shevchenko A, Knoblich JA (2000) A protein complex containing inscuteable and the galpha-binding protein pins orients asymmetric cell divisions in Drosophila. Curr Biol 10:353-362.

Schober M, Schaefer M, Knoblich JA (1999) Bazooka recruits Inscuteable to orient asymmetric cell divisions in Drosophila neuroblasts. Nature 402:548-551.

Shen CP, Knoblich JA, Chan YM, Jiang MM, Jan LY, Jan YN (1998) Miranda as a multidomain adapter linking apically localized Inscuteable and basally localized Staufen and Prospero during asymmetric cell division in Drosophila. Genes Dev 12:1837-1846.

Siderovski DP, Diverse-Pierluissi M, De Vries L (1999) The GoLoco motif: a Galphai/o binding motif and potential guanine-nucleotide exchange factor. Trends Biochem Sci 24:340-341.

Spana EP, Doe CQ (1995) The prospero transcription factor is asymmetrically localized to the cell cortex during neuroblast mitosis in Drosophila. Development 121:3187-3195.

Spradling AC (1986) P-element mediated transformation. In: Drosophila: a practical approach (Roberts DB, ed), pp 175-197. Oxford, UK: IRL.

Takesono A, Cismowski MJ, Ribas C, Bernard M, Chung P, Hazard III S, Duzic E, Lanier SM (1999) Receptor-independent activators of heterotrimeric G-protein signaling pathways. J Biol Chem 274:33202-33205.

Tio M, Zavortink M, Yang X, Chia W (1999) A functional analysis of inscuteable and its roles during Drosophila asymmetric cell divisions. J Cell Sci 112:1541-1551.

Truman JW, Bate M (1988) Spatial and temporal patterns of neurogenesis in the central nervous system of Drosophila melanogaster. Dev Biol 125:145-157.

Truman JW, Taylor B, Awad T (1993) Formation of the adult nervous system. In: The development of Drosophila melanogaster (Bate M, Martinez Arias A, eds), pp 2145-1276. Cold Spring Harbor, NY: Cold Spring Harbor Laboratory.

Vaessin H, Grell E, Wolff E, Bier E, Jan LY, Jan YN (1991) prospero is expressed in neuronal precursors and encodes a nuclear protein that is involved in the control of axonal outgrowth in Drosophila. Cell 67:941-953.

Wodarz A, Ramrath A, Kuchinke U, Knust E (1999) Bazooka provides an apical cue for Inscuteable localization in Drosophila neuroblasts. Nature 402:544-547.

Woods DF, Wu JW, Bryant PJ (1997) Localization of proteins to the apico-lateral junctions of Drosophila epithelia. Dev Genet 20:111-118.

Yu F, Morin X, Cai Y, Yang X, Chia W (2000) Analysis of partner of inscuteable, a novel player of Drosophila asymmetric divisions, reveals two distinct steps in inscuteable apical localization. Cell 100:399-409.

Zwaal RR, Ahringer J, van Luenen HG, Rushforth A, Anderson P, Plasterk RH (1996) G proteins are required for spatial orientation of early cell cleavages in C. elegans embryos. Cell 86:619-629. 